\title{
An Assessment of Learners' Engagement in Mathematics: Towards Building Mathematics Culture in South African Schools
}

\author{
Bernard Moeketsi Hlalele* \\ Department of Business Support studies, Central University of Technology, Republic of South Africa
}

Received: May 07, 2018; Published: May 21, 2018

*Corresponding author: Bernard Moeketsi Hlalele, Department of Business Support studies, Central University of Technology, Free State Private Bag X20539 Bloemfontein 9300, Republic of South Africa

\begin{abstract}
South Africa is the highest ranked emerging economy in Africa there being one of the most promising emerging markets globally. In the current highly technological economic world, mathematics education and mathematics performance are key resources in the global competition. This study used a modified Venn diagram model of student engagement to assess the level of engagement of learners in Mathematics. This study used a case study research design to assess the level of student engagement in mathematics. A sample of 80 high school leaners was drawn from grades 8, 10, 11 and 12. Responses were captured in SPSS and reliability was run whose results were a Cronbach's Apha coefficient of 0.808 , that is way above the threshold value of 0.7 .

After grouping that was aided by scores and by deciles, the results showed that leaners are not engaged in mathematics teaching and learning. An ANOVA test was run between groups to check differences in means, the results showed a significant difference at 0.05 with $P$ $=0,008471<0.05$. A further test was conducted, this post hoc test showed all grades having equal means except grade 10 which revealed a significant difference with grade 11. This was however inconsistent with the performance levels these respondents obtained in their previous years. The conclusion was that all the respondents showed disengagement in mathematics teaching and learning. These results on the other hand are therefore consistent with the literature that shows South Africa far below other countries in global competitiveness in terms of mathematics. The study therefore recommends that authorities and all other relevant stakeholders adopt top-learner-performance countries such Singapore as shown in the brief literature review below.
\end{abstract}

Keywords: Learners' Engagement; Mathematics Culture

\section{Introduction}

School is central to the daily lives of many youths, in a sense that they view it as their long-term wellbeing and this attitude is embedded in their participation in both academic and non-academic pursuits. However, some youth do not share the above mentioned viewpoint, they do not believe that academic success will have a strong bearing on their future. These feelings and attitude may result in a disruptive behavior towards teachers and other students [1]. Meeting youths' needs is perhaps a major challenge in the 21st century facing teachers and school administrators. Researchers have devised a term, engagement that refers to the extent to which students identify the value of schooling outcomes, and participate in academic and non-academic school activities [1]. Student engagement has to date almost become a buzz word not only in traditional conventional systems but in all spheres of education [2]. Several studies have proven learners' engagement to be highly correlated with improvements in specific desirable outcomes that include; general abilities and critical thinking, practical competence and transferability, cognitive development, improved grades and learners 'satisfaction leading to participation in both academic and non-academic activities $[1,3,4]$.

In addition to this, researchers, teachers and policy makers have increasingly focusing on leaners' engagement as a key tool for addressing low achievement problems, learners boredom and alienation and high failure and dropout rates [5]. The country's general competence in mathematics is regarded as a major component of the economic success and the level of mathematics knowledge in the population had a direct link with the Gross Domestic Product (GDP) [6]. Mathematics has not only got a place in economy but also in social sciences as well in political debate as a contribution to conduct of rational debate. It also has impacted 
positively in forensic sciences through crime detection, which is one of the economic issues that retard the social and economic development (Woodrow, 2003:1). Two of the South African Department of Basic Education goals for 2030 at from 2015 to 2019 are; goal 5: Increase the number of Grade 12 learners who pass mathematics and Goal 6: Increase the number of Grade 12 learners who pass physical science [7]. It is through education, that nations have better skills, autonomous workers that are able to use their education for creativity, building of wealth as well as putting pressures off government economic programs $[8,9]$.

However, South Africa is currently facing a downward trend in the world competitiveness rankings, especially in the factors such as economic growth where she ranked 56th in 144 countries and performed poorly on high education and training and ranked 144th in labour-employer relations [10]. In a report by the World Economic Forum (WEF) South Africa was ranked last in 148 countries in mathematics and science and 146th for overall quality of her education, however these results were slummed by the Department Basic Education (DBE) that they were not credible and accurate as the methodology followed was based on the opinions of business leaders who were not even experts in the field [11]. Surprisingly, in a 2013 ANA Diagnostic Report whose main aim was to determine learners' performance on knowledge and skills as a result of both learning and teaching, the department of basic education found low levels of competency [12]. In 2012 and 2013 the National average percentage scores in Mathematics were $13 \%$ and $14 \%$ respectively for 9 th graders [13]. Given the above context, it is imperative that an evaluation of the level of leaners engagement is conducted to; assess the level of student engagement, ascertain the factors that impact positively on student engagement in a South Africa context, identify the factors that lead to student disengagement and recommend strategies to enhance student engagement. The results from this study are therefore hoped to contribute in increasing learners' engagement in mathematics hence the country's economic growth.

\section{Brief Literature Review}

Student engagement has received a global attention in the $21^{\text {st }}$ century probably due to well established robust correlations with students' academic achievement and development that include satisfaction, persistence and social engagement [9]. However, this phenomenon has defined differently by various scholars. The following are some of the definitions of student engagement. Student engagement is concerned with the interaction between the time, effort and other relevant resources invested by both students and their institutions intended to optimize the student experience and enhance the learning outcomes and development of students and the performance, and reputation of the institution $[3,14]$.

Davis, (n.d) argues that student engagement is a three dimensional concept and this entail, relational engagement (where leaners engage with the classroom and school community), behavioral engagement (encompasses students' effort, persistence, participation, and compliance with school structures) and cognitive engagement (how students feel about themselves and their work, their skills, and the strategies they employ to master their work). There is actually very little consensus on how student engagement is defined however, one thing agreed upon is that it is not one-dimensional. It involves cognitive, behavioral and affective components (Sri kanthan, (n.d).

\section{Strategies That Promote Learner Engagement in STEM}

Many believe that the key to strengthening any nation's economy and competing globally chiefly lies in the fostering innovative culture and educating youth in science, technology, engineering and mathematics (STEM) [15]. Studies in United States have shown that hands-on activities, campaigns designed to arouse interest in youth have resulted in an increase in performance in STEM.Some of these activities include; taking field trips where experiments are conducted, teachers who enjoy their subjects and motivate and encourage learners to partake in STEM. One of the most powerful strategies that US uses to engage its youth in STEM is through innovation teams of high school learners, teachers and mentors that are given up to $\$ 10,000$ each to invent technological solutions to real world problems [15]. Similarly, Taylor and Parsons [16] assert that today's learners want to connect and communicate constantly and need an environment that supports these connections. In Singapore, the world leading country in the Mathematics, Science and Technology, the following strategies in the table below are implemented to ensure increased engagement in STEM at all education levels (Table 1).

Table 1: Some of the Singapore's strategies in boosting STEMSource: Idris, (2013).

\begin{tabular}{|c|c|}
\hline Strategy & Description \\
\hline Integrated program & $\begin{array}{c}\text { Where talented learners are selected and exempted from intermediate national examinations to } \\
\text { university. }\end{array}$ \\
\hline Teach less, learn more & $\begin{array}{l}\text { The strategy aims to 'touch the hearts and engage the minds of learners by promoting a different learning } \\
\text { paradigm in which there is less dependence on rote learning, repetitive tests and instruction, and more on } \\
\text { engaged learning, discovery through experiences, differentiated teaching, learning of lifelong skills, and } \\
\text { the building of character through innovative and effective teaching approaches and strategies }\end{array}$ \\
\hline Teaching talent is identified and nurtured & $\begin{array}{l}\text { The approach has been developed to enhance education delivery by focusing on selecting, training, } \\
\text { compensating and developing teachers and principals. }\end{array}$ \\
\hline Training of school leaders & $\begin{array}{l}\text { Their young teachers are continuously assessed based on leadership potential, where opportunities } \\
\text { to develop their leadership capacity were provided by the government. In the education system, all } \\
\text { education leadership positions are part of their teaching-career structure. More experienced school } \\
\text { leaders mentor newly appointed leaders. }\end{array}$ \\
\hline
\end{tabular}




\begin{tabular}{|c|c|}
\hline $\begin{array}{c}\text { Primary students are given strong } \\
\text { foundation in science and mathematics }\end{array}$ & $\begin{array}{c}\text { A clear pathways and educational link is set in place to expand their career path in STEM based } \\
\text { disciplines. Specialised independent schools have been set up to propel students into various scientific } \\
\text { lead by National University of Singapore. }\end{array}$ \\
\hline $\begin{array}{c}\text { High-tech infrastructure to enhance STEM } \\
\text { based education }\end{array}$ & $\begin{array}{c}\text { Singapore Science Park, Biopolis and Fusionopolis (state-of-the-art research facilities in the country to } \\
\text { support the growth of the economy), teacher quality (high performers), ICT integration in teaching, }\end{array}$ \\
\hline The A*STAR resource web portal & The country has developed their own research database known as the Singapore Researchers Database. \\
\hline STEM education programs & National Junior Robotics Competition, Science in the Mall, Meet the Scientist, \\
\hline
\end{tabular}

Science actually means business, moving to a business culture that values science-based strategies is more highly to create a greater diversity of career prospects for science and engineering graduates in the country [17]. Similarly, it is estimated $75 \%$ of the

Table 2: Some of the strategies used in boosting STEM in other countries Source: Department of Education, Science and Training. 2003: Stephens, 2009: White, 2011.

\begin{tabular}{|c|c|c|}
\hline Country & Program & Description \\
\hline Australia & Teachers'Research\& Development & $\begin{array}{l}\text { Teachers undertake a research in the industry lead by a scientist or } \\
\text { Engineer which gives fresh insights and motivation when they come back } \\
\text { to classroom. Career information for teachers to become career advisors } \\
\text { to their students }\end{array}$ \\
\hline United States & Afterschool program & $\begin{array}{l}\text { "We use visual arts, music, } \\
\text { dance, theater arts and the } \\
\text { written word to engage our } \\
\text { students in creative pursuits, } \\
\text { academic learning, violence } \\
\text { prevention and community } \\
\text { service. Our program has } \\
\text { increased the students' in-school attendance and significantly } \\
\text { improved their academic } \\
\text { achievement." }\end{array}$ \\
\hline
\end{tabular}

\section{Methods and Materials}

A 5 point likert scale questionnaire was administered to all participants of a selected school in Thaba Nchu. The sample size of 80 leaners drawn from various grades, 8, 10,11 and 12 was chosen. The study used a modified Venn diagram student engagement model where scores were aggregated per respondent per statement. The scores were categorized in deciles with corresponding level of engagement. All scores from normal to lower values were regarded as disengagement. An ANOVA test was conducted to check if any differences existed between groups. This was followed by a Post Hoc test to seek deeper understanding of which groups differ in means.

\section{Results}

From the Tables 3-5 above it can be seen that $65 \%$ (52) of the respondents have normal to strongly disengagement leading to a conclusion that these leaners are not engaged in mathematics. fastest growing populations 'occupancy needs STEM skills and knowledge [18]. The following table shows some of these strategies used in other countries (Table 2).

Table 4: Item-Total Statistics.

\begin{tabular}{|c|c|c|c|c|}
\hline & $\begin{array}{c}\text { Scale Mean if Item } \\
\text { Deleted }\end{array}$ & $\begin{array}{l}\text { Scale Variance if } \\
\text { Item Deleted }\end{array}$ & $\begin{array}{l}\text { Corrected Item-Total } \\
\text { Correlation }\end{array}$ & $\begin{array}{l}\text { Cronbach's Alpha } \\
\text { if Item Deleted }\end{array}$ \\
\hline Level & 57 & 215.19 & 0.273 & 0.805 \\
\hline I think what we are learning in school (maths) is interesting & 56.04 & 209.252 & 0.308 & 0.804 \\
\hline I like what i am learnig at school & 55.92 & 201.994 & 0.486 & 0.793 \\
\hline
\end{tabular}

Tables $6 \& 7$ shows the results of one-way ANOVA and the null hypothesis that three grades means are equal is rejected at 0.05 significant level, hence revealing a significant difference in means in these grades since $\mathrm{p}=0.008471<0.05$. From the above Tables $8 \& 9$ it can be deduced that grades 8,10 and 12 form one subset with their p-values showing non-significant differences. However, grade 10 seems to be significantly different from the grade 11 . The following table tracks the possible reasons for this. It is then evident that grade 10 mean is likely to be different because $100 \%$ of its respondents showed engagement in mathematics yet the whole study revealed disengagement. This is also contradicting the performance levels these leaners got in their previous grade [1924].

Table 3: Reliability Statistics.

\begin{tabular}{|c|c|}
\hline Cronbach's Alpha & N of Items \\
\hline .808 & 19 \\
\hline
\end{tabular}




\begin{tabular}{|c|c|c|c|c|}
\hline I think learning maths is boring & 58.29 & 220.537 & 0.209 & 0.807 \\
\hline I enjoy learning maths in class & 55.55 & 210.403 & 0.441 & 0.797 \\
\hline I like my school & 55.75 & 202.342 & 0.461 & 0.794 \\
\hline I am proud to be in this school & 55.59 & 213.03 & 0.277 & 0.805 \\
\hline Most mornings, I look forward to going to school & 56.41 & 202.397 & 0.406 & 0.798 \\
\hline I am happy to be in this school & 55.82 & 204.728 & 0.45 & 0.795 \\
\hline I try hard to do well in school & 55.35 & 206.965 & 0.488 & 0.794 \\
\hline When i am in class i participate in class activities & 56.28 & 204.455 & 0.413 & 0.797 \\
\hline When i am in class, i just act like $\mathrm{i}$ am working & 58.05 & 220.504 & 0.19 & 0.808 \\
\hline When I am in class, my minder wanders & 58.2 & 222.365 & 0.085 & 0.815 \\
\hline $\begin{array}{l}\text { When i study i try to connect what } \mathrm{i} \text { am learning with my } \\
\text { experinces }\end{array}$ & 56.22 & 206.278 & 0.409 & 0.798 \\
\hline When i study, i figure out how the information & 56.59 & 194.853 & 0.548 & 0.788 \\
\hline $\begin{array}{l}\text { When i study i try to understand the material better in } \\
\text { relating i know }\end{array}$ & 55.97 & 204.632 & 0.49 & 0.793 \\
\hline $\begin{array}{l}\text { I try to understand how things I learn fit together with each } \\
\text { other }\end{array}$ & 56.28 & 199.594 & 0.529 & 0.79 \\
\hline $\begin{array}{l}\text { I try to match what i already know with things i am trying to } \\
\text { learn in maths at school }\end{array}$ & 56.71 & 197.018 & 0.484 & 0.793 \\
\hline $\begin{array}{l}\text { When studying, i try to combine different pieces of } \\
\text { information from cource material in a new way }\end{array}$ & 57 & 209.316 & 0.273 & 0.807 \\
\hline
\end{tabular}

Table 5: Deciles.

\begin{tabular}{|c|c|c|c|c|}
\hline Deciles (\%) & Description & Total scores Frequency & Cumulative Frequency & Percentage \% \\
\hline Deciles 10-20 & Strongly disengaged & 3 & 3 & $4 \%$ \\
\hline Deciles 30-40 & Moderately disengaged & 12 & 15 & $15 \%$ \\
\hline Deciles 50-60 & Normal engagement & 37 & 72 & $46 \%$ \\
\hline Deciles 70-80 & Moderately engaged & 27 & 80 & $34 \%$ \\
\hline Deciles 90-100 & Strong engagement & 1 & $1 \%$ \\
\hline
\end{tabular}

Table 6: ANOVA summary.

\begin{tabular}{|c|c|c|c|c|}
\hline SUMMARY & & & & Average \\
\hline Groups & Count & Sum & 63 & Variance \\
\hline Grade 8 & 12 & 756 & 71,5 & $1,030,909,091$ \\
\hline Grade 10 & 10 & 715 & 55 & $1,708,571,429$ \\
\hline Grade 11 & 43 & 2365 & 62,2 & $1,238,857,143$ \\
\hline Grade 12 & 15 & 933 & & \\
\hline
\end{tabular}

Table 7: ANOVA Results.

\begin{tabular}{|c|c|c|c|c|c|}
\hline ANOVA & & & & & \\
\hline Source of Variation & SS & df & MS & F & P-value \\
\hline Between Groups & $2,566,088$ & 3 & $8,553,625$ & $4,188,387,916$ & 0,008471 \\
\hline Within Groups & 15520,9 & 76 & $2,042,224$ & & \\
\hline Total & 18086,99 & 79 & & & \\
\hline
\end{tabular}

Table 8: Two-tailed t-test, p-values between groups (grades), Post hoc test.

\begin{tabular}{|c|c|c|c|c|}
\hline & Grade 8 & Grade 10 & Grade 11 & Grade 12 \\
\hline Grade 8 & & 0,287842 & 0,119523 & 0,904547 \\
\hline Grade 10 & & & 0,000538 & 0,050824 \\
\hline Grade 11 & & & & 0,062125 \\
\hline Grade 12 & & & & \\
\hline
\end{tabular}


Table 9: Grade 10 and 11 deciles and frequency grouping.

\begin{tabular}{|c|c|c|}
\hline \hline Deciles & \multicolumn{2}{|c|}{ Frequencies } \\
\hline $1-2$ & Grade 10 & Grade 11 \\
\hline $3-4$ & 0 & 3 \\
\hline $5-6$ & 0 & 12 \\
\hline $7-8$ & 3 & 37 \\
\hline $9-10$ & 6 & 27 \\
\hline
\end{tabular}

\section{Conclusion}

In conclusion the study which was aimed at assessing the level of engagement of leaners in mathematics. The study has revealed that there is still a good amount of work to be done to achieve a satisfactory performance in mathematics. The results are however consistent with the literature on how South Africa fairs internationally. It is therefore recommended that authorities and all other stakeholders align their strategies with those of the top performing countries such as Singapore.

\section{References}

1. Willms JD (2000) Student engagement at school a sense of belonging and participation, results from PISA 2000. organisation for economic cooperation and development (OECD).

2. Ndudzo D (2013) An Evaluation of Student Engagement in the Odl Higher Education Context in Zimbabwe. Journal of Business and Management 15(2): 57-64.

3. Trowler V (2010) Student engagement literature review. Lancaster University, The higher Education Academy.

4. Jennings JM, Angelo T (2006) Student engagement: Measuring and enhancing engagement with learning. New Zealand Universities Academic Audit Unit, New Zealand.

5. Fredricks J, McColskey W, Meli J, Mordica J, Montrosse B, et al. (2011) Measuring student engagement in upper elementary through high school: a description of 21 instruments.

6. Robert L (2010) Learn mathematics to boost economy, Scientist advises.

7. (2015) Department of Basic Education (2015) Action Plan to 2019: Towards the realization of Schooling 2030. Pretoria, South Africa.
8. Wright J (2010) The relationship between education and the economy.

9. Taylor S (2010) How does socio-economic status impact on educational outcomes in South Africa?

10. Maswangani N (2014) South Africa falls in competitiveness index.

11. Wilkinson K (2014) is South Africa bottom of the class in maths and science? WEF ranking is meaningless.

12. (2013) Department of Basic Education (2013a) 2013 Diagnostic Report and 2014 framework for improvement. Pretoria, South Africa.

13. (2013) Department of Basic Education (2013b) Report on Annual National Assessment of 2013: Grade 1 to 6 and 9. Pretoria, South Africa.

14. Walker L, Logan A (2008) Learner engagement: A review of learner voice initiatives across the UK's education sectors. Futurelab, UK.

15. Lemelson-MIT Program (2010) Survey reveals ways to enhance teens' interest in science, technology, engineering and mathematics.

16. Taylor L, Parsons J (2011) Improving Student Engagement. Current Issues in Education 14(1): 1-33.

17. Stephens M (2009) Numeracy in practice: teaching, learning and using mathematics. Department of Education and Early Childhood Development. Melbourne, Australia, UK.

18. Office of the Chief Scientist (2013) Science, Technology, Engineering andMathematics in the National Interest: A Strategic Approach, AustralianGovernment, Canberra, Australia, Uk.

19. (2003) Department of Education, Science and Training (2003) equipping young Australians to lead us to the future. Canberra, Australia, Uk.

20. Davis C (2016) What does it mean for students to be engaged?

21. Idris DN, Daud MF, Meng C, Eu LK (2013) Consultant Report Securing Australia's Future STEM: Country Comparisons. Australian Council of Learned Academies. Australia, UK.

22. (2012) South Africa Department of Basic Education, 2012 A parent's guide to schooling.

23. Sri kanthan (2008) Strengthening student engagement in the classroom. Singapore: NUS: (MSc-Dissertation)

24. White D (2011) Providing multiple benefits to middle school students, middle school and science, technology, engineering and math (STEM) key to health and wellness for pre-teens and teens supporting career and college pathways for middle school age youth. Met Life Foundation.

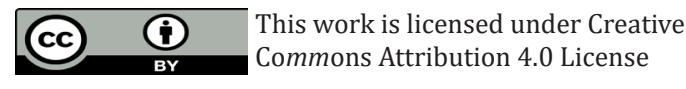

Submission Link: https://biomedres.us/submit-manuscript.php

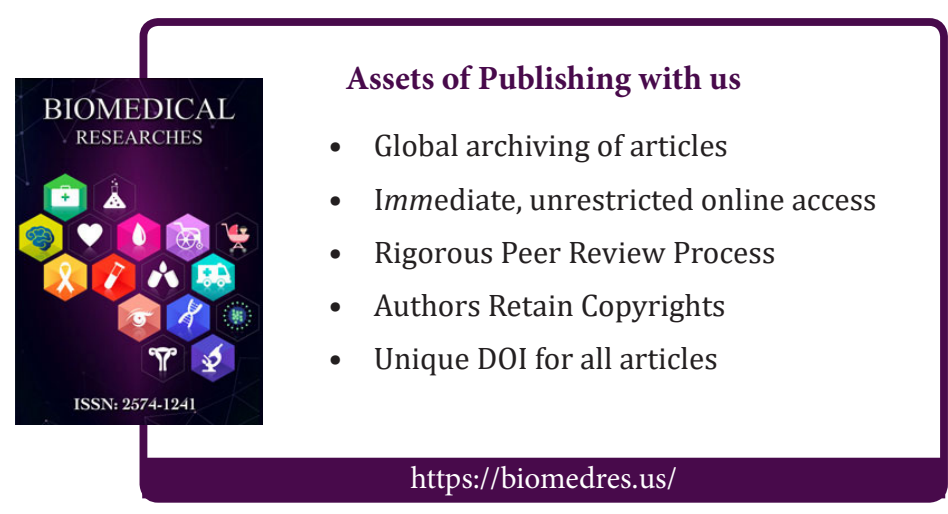

